Extended Abstract

\title{
Designing for sharing communities: from rhetoric to reality
}

\section{Geraldine Fitzpatrick*}

Vienna University of Technology (TU Wien) / Argentinierstrasse 8 187-2, 1040 Vienna.

E-Mail: geraldine.fitzpatrick@tuwien.ac.at

* Author to whom correspondence should be addressed; Tel.: +43-1-58801-18735; Fax: +43-1-5880118793

Accepted:

\section{Introduction}

While forms of peer-to-peer exchange have existed throughout human history, there has been an explosion of interest in the sharing economy and peer-to-peer exchange in recent times. This rise has been enabled in particular by web and mobile technologies, with examples of online-mediated sharing services including Craigslist, Airbnb, car sharing services, food sharing, tool sharing and so on. As noted in a March 2013 article on the rise of the sharing economy in The Economist": "technology has reduced transaction costs, making sharing assets cheaper and easier than ever-and therefore possible on a much larger scale. The big change is the availability of more data about people and things, which allows physical assets to be disaggregated and consumed as services."

The disruptive impacts of these new services are also gaining increased public and governmental attention, especially monetised exchange services such as in AirBnB and Uber. Governments world wide are starting to react to concerns about changes to local neighbourhoods and about changes to tax revenues, setting up review commissions ${ }^{2}$ and making legislative changes.

1 "The rise of the sharing economy", The Economist, Mar 9 2013. Available from http://www.economist.com/news/leaders/21573104-internet-everything-hire-rise-sharing-economy [Last accessed 15 May 2015].

${ }^{2}$ Dept for Business Innovation and Skills. Independent report: Sharing economy review: terms of reference. Retrieved from: https:/www.gov.uk/government/publications/sharing-economy-reviewterms-of-reference/sharing-economy-review-terms-of-reference [Last accessed 15 May 2015] 
The motivations to participate in such sharing and exchange services are wide and varied, and often conflicting (Shih et al, 2015). One critique of many of the more monetized services is that they are becoming increasingly driven from a profit motive and have lost touch with some of the initial idealism and motivations around these services, such as promoting sustainability through the sharing or collaborative consumption of resources, or promoting social connectivity and community building.

However for many people, the more altruistic and community/sustainability oriented motives still hold and exchange services such as time banking and food sharing are also the gaining increasing attention (Light and Miskelly, 2014) as people explore new possibilities for civic engagement, collaborative consumption and welfare structures. A key feature of these services is their focus on the more local community level. Another key feature is that exchanges are not monetized but valued in other ways. It would be more accurate here then to talk about the sharing community rather than the sharing economy.

However, how to 'do' such new services well, and how to design technologies to best support such services is still a matter of trial and error and reflection (Malmborg et al, 2015). What is becoming increasingly clear though from the literature and case studies of such communities is that the shift from the idealist rhetoric of sharing and community to the day-to-day realities of making such a service work is non-trivial. Just having a good technical support platform is not enough. Regardless of platform, or of any particular model of sharing exchange, there is significant ongoing effort needed to establish, maintain and grow a service, not only focussing on the practical aspects of the service but on also building trust and growing a community, and accessing relevant resources and infrastructures.

Contributing to these reflections, I will focus particularly on not-for-profit and non-monetised exchange services and explore the issues entailed in establishing and running these new forms of exchange, how technologies are being used as enablers, and what lessons can be learnt to date. To do this I will draw on some of our own and other's research into various sharing communities, including food sharing (Ganglbauer et al, 2014), timebanking (Bellotti et al 214) and enabling sharing that engages older people as active participants (related to the AAL 'Given and Take' project ${ }^{3}$ ).

Issues to be explored include how to establish new sharing communities, the organisational work to make a service work, the impact of funding and sponsorship models, the choice for model of exchange service, how to create new cultural norms and build sustained engagement. These findings have implications not just for the design of technical platforms to support services, but more critically in the design of the services that will realize the impact or not of such technologies in use.

\section{Acknowledgments}

I thank the partners, collaborators and participants in the EU AAL-funded 'Give and Take' project, in particular Lone Malmborg, Oezge Subasi, Naemi Luckner, Katharina Werner; also thanks to Eva Ganglabauer who undertook the research around food sharing as part of her $\mathrm{PhD}$ work.

\section{References and Notes}

${ }^{3}$ Give\&Take - Designing a reciprocal exchange service for a good and engaged senior life. EU/AAL project 2014-2017. http://givetake.eu/ 
1. Bellotti, V.; Cambridge, S.; Hoy, K.; Shih, P.; Handalian, L.; Han, K.; Carroll. J. Towards Community-Centered Support for Peer-to-Peer Service Exchange: Rethinking the Timebanking Metaphor. In Proc. CHI 2014, ACM Press, New York, 2014; pp. 2975-2984.

2. Ganglbauer, E.; Fitzpatrick, G.; Subasi, O.; Güldenpfennig, F. Think Globally, Act Locally: A Case Study of a Free Food Sharing Community and Social Networking. In Proc. CSCW'2014, ACM Press, New York, 2014; pp. 911-921.

3. Light, A.; Miskelly, C. Design for Sharing. Northumbria University / The Sustainable Society Network, Nov 2014.

4. Malmborg, L.; Light, A.; Fitzpatrick, G.; Bellotti, V.; Brereton, M. Designing for Sharing in Local Communities. In Pro.c CHI EA'15, ACM Press New York, 2015; pp. 2357-2360.

(C) 2015 by the authors; licensee MDPI and ISIS. This abstract is distributed under the terms and conditions of the Creative Commons Attribution license. 